\title{
Dietary Supplementation of Citric acid (monohydrate) Improves Health Span in Drosophila melanogaster
}

\author{
Komal Panchal ${ }^{\mathrm{a}}$, Kesha Patel ${ }^{\mathrm{b}}$, Anand K. Tiwari ${ }^{\mathrm{a} *}$ \\ ${ }^{a}$ Genetics \& Developmental Biology Laboratory, School of Biological Sciences \& Biotechnology, Indian Institute of Advanced Research/UIAR, \\ Koba Institutional Area, Gandhinagar-382007, Gujarat, India. ${ }^{\mathrm{b}}$ Sardar Vallabhbhai Patel University, Anand, Gujarat, India.
}

\section{ARTICLE INFO}

Article history:

Received on: 26/01/2016

Revised on: 23/02/2016

Accepted on: 29/03/2016

Available online: 21/04/2016

Key words:

Drosophila melanogaster; Citric acid monohydrate;

Body weight; Locomotor;

Oxidative stress; Fatty acid

synthesis.

\begin{abstract}
Citric acid is a biochemical compound present in variety of citrus fruits. Citrate plays a vital role in production of energy (ATP) via Tricarboxylic acid (TCA) cycle and also involve in Fatty acid (FA) synthesis in cytoplasm. The objective of this study is to evaluate the effect of citric acid supplementation on health span in Drosophila melanogaster. Oregon $R^{+}$fly used in most of the experiments. Body weight of male and female flies fed on normal and citric acid mixed diet was determined, locomotor assay and anti-oxidant activity associated with citric acid was measured by performing superoxide dismutase (SOD) and catalase (CAT) enzymatic assay. Fat content in citric acid fed flies was evaluated by Oil Red O staining in fat body tissues of adult Drosophila. Reverse trascriptase PCR (RT-PCR) analysis was performed to check the expression level of Brummer (bmm) and Fatty acid Synthase (FAS) genes. In the present study we have shown that supplementation of citric acid reduces body weight of male and female flies, improves locomotor activity of Alzheimeric flies, reduces oxidative stress and increases FA synthesis in Drosophila. Here, we concluded that supplementation of citric acid (monohydrate) improves health span in Drosophila.
\end{abstract}

\section{INTRODUCTION}

Citric acid is a biochemical compound and one of the major products of Citrus family. Citric acid is present in variety of fruits such as lemon, lime, oranges, grapes, kiwis, strawberries, apple, pears, raspberries and also available in vegetables and plants (roots \& leaves) [1,2]. It is commonly used as a food additive to provide acidity and sour taste to foods and beverages, also used as an acidity regulator [3]. Citrate is a weak acid and plays an essential role in production of energy (in the form of ATP) via mitochondrial Krebs' or tricarboxylic acid (TCA) cycle. It is synthesized in mitochondria by Kreb's cycle (TCA cycle) and comes out in the cytoplasm with the help of citrate transporter to provide cellular energy in the form of ATP

\footnotetext{
* Corresponding Author Anand Krishna Tiwari, Assistant Professor, Genetics \& Developmental Biology Laboratory, School of Biological Sciences \& Biotechnology, Indian Institute of Advanced Research/IAR, University Koba Institutional Area, Gandhinagar-382007, Gujarat, India. Email:aktbhu@gmail.com
}

$[4,5]$. In addition, citrate also provides $\mathrm{NAD}^{+}$, required for the glycolysis [6]. The other role of citrate is the synthesis of AcetylCoA, the lipid building block and converts it into malonyl acid for formation of fatty acid (FA) and sterols [7]. Citrate is also known to play a vital role in maintenance of normal brain function as a neurotransmitter precursor and in energy production $[6,8]$. It is well studied that supplementation of antioxidant compound protects cells against the damaging effect of Reactive Oxygen Species (ROS) [9]. Antioxidant compounds such as vitamin C, E, carotenoids and several polyphenolic compounds used as dietary supplements have ability to scavenge the oxygen free radicals and save the cells from any damage i.e. lipid peroxidation, protein oxidation and DNA damage [10]. Herbs, plants and plants based components are rich source of antioxidant and used from ancient time to treat several human diseases. Citric acid synthesized naturally (from lemon, orange) and intracellular during metabolism, act as an antioxidant and present in many foods i.e. jelly sweet, jam, marmalade, baked nutrients, candy, soft drinks, tinned vegetable and fruit food [11]. In the present study, we used Drosophila melanogaster as an animal model to study the effect of citric acid on physiology of Drosophila melanogaster. 
Drosophila melanogaster commonly known as "fruit fly" is one of the oldest animal models (more than 110 years) with fully sequenced genome [12]. It has shorter life cycle (10-12 days at $25^{\circ} \mathrm{C}$ ), lesser no. of chromosomes (4 pair of chromosomes), high fecundity (females lay $\sim 800$ eggs in a life time), ease to handle and possess $\sim 75 \%$ homology with human disease genes $[13,14]$. After genome sequencing in 2000, It was inferred that Drosophila is one of the closest invertebrate models to the human [15] Drosophila has a complex nervous system [16], complex behavior and exhibit daily cycles of activity and inactivity, a behavioral rhythm governed by animal's endogenous circadian system. In recent years, Drosophila has been used as a model of choice to study the basic mechanism of neurodegenerative disease, circadian rhythms and in search of medicinal property of different medicinal plants [17-21].

In this study, using Drosophila melanogaster as an animal model, we have shown that, supplementation of citric acid mixed diet reduces body weight, improves locomotor activity, reduces oxidative stress and increases fatty acid synthesis in Drosophila. Thus, on the basis of the results it was concluded that dietary supplementation of citric acid improves health span in Drosophila melanogaster.

\section{MATERIALS AND METHODS}

\subsection{Compound name}

Chemical compound studied in our work is Citric acid monohydrate (PubChem CID: 22230)

\subsection{Fly strains and culture conditions}

Oregon $R^{+}$(wild type) strain of Drosophila melanogaster was used for most of the experimental studies conducted in this paper. We also used $G M R A \beta_{42}{ }^{K 52} ; \mathrm{G} M R A \beta_{42}{ }^{K 53}$ a transgenic Drosophila line that over-express Amyloid $\beta_{42}$ protein in Drosophila melanogaster and used Drosophila model of Alzheimer's Disease (AD). This fly stock was used to examine the effect of citric acid on locomotor activity in AD flies.

The flies were cultured at $22 \pm 1^{\circ} \mathrm{C}$ in BOD incubator.

\subsection{Drosophila culture medium}

The flies were cultured on Drosophila food medium containing agar-agar, corn meal, sugar, yeast, propionic acid (antibacterial), and nepagin (anti-fungal agent). One unit $(360 \mathrm{~mL})$ of Drosophila food was prepared by dissolving the $3 \mathrm{~g}$ agar-agar (SRL, Cat\# 0140186), 17g corn meal, 15g sugar, 6g yeast, 1mL propionic acid (Merck) and 1g nepagin (Methyl-phydroxybenzoate sodium salt, Himedia, Cat\# GRM129-500G) in water and total volume was make up to $360 \mathrm{~mL}$. The additional yeast suspensions were provided for healthy growth.

\subsection{Preparation of citric acid (monohydrate) containing food}

Citric acid (monohydrate) (SRL Cat\# 0348216) mixed diet were prepared by dissolving varying concentration of citric acid solution $(0.15 \mathrm{M}, 0.3 \mathrm{M}, 0.45 \mathrm{M}$ and $0.6 \mathrm{M})$ in normal Drosophila food media (Normal diet/food). The food was properly mixed and poured in Drosophila culture vials and bottles and allowed to dry for further use.

\subsection{Body weight determination}

The body weight of flies fed on normal diet (without citric acid) and on citric acid mixed diet was measured by taking the weight (in grams) of flies. For this, first the weight of empty eppendorf tube $(1.5 \mathrm{~mL})$ was measured and noted as initial weight $\left(I_{w}\right)$ and the weight of eppendorf with 20 flies noted as final weight $\left(F_{w}\right)$. The weight of empty eppendorf was subtracted from the weight of eppendorfs with flies $\left(F_{w}-I_{w}\right)$. Assay was repeated 5 times for each group. The mean body weight of flies were calculated and it was divided by total number of flies used in the assay $\left(F_{w}-I_{w} /\right.$ No. of flies taken). Total 100 male and 100 female flies were taken from control and experimental group for weight analysis.

\subsection{Locomotor Assay}

The locomotor assay of OregonR ${ }^{+}$and $G M R A \beta_{42} K^{52}$; $G M R A \beta_{42} K^{53}$ flies fed on normal and citric acid mixed Drosophila diet were performed as described by [22] with little modification. For this, 20 flies of 10 and 20 days age group were chosen and flies were placed in vertical glass tube $(30 \mathrm{~cm}$ long x $1.5 \mathrm{~cm}$ wide) and allowed to acclimatize for $2 \mathrm{~min}$. Flies were tapped gently to the bottom of the vial. The number of the flies crosses $10 \mathrm{~cm} /$ 10 seconds were counted. This was repeated five times. Total 100 flies from each group (control \& experimental) were used for the locomotor assay. The assay was performed at $25^{\circ} \mathrm{C}$ under standard lighting condition.

\subsection{Enzymatic Assay}

This was done to see the effect of citric acid supplementation on antioxidant enzymes such as Superoxide Dismutase (SOD) \& Catalase (CAT) activities in Drosophila melanogaster.

\subsection{Preparation of protein sample}

The protein samples were prepared by homogenizing 1020 flies fed on normal diet and diet mixed with $0.15 \mathrm{M}, 0.3 \mathrm{M}$, $0.45 \mathrm{M}$ and $0.6 \mathrm{M}$ citric acid monohydrate in $100 \mathrm{mM} \mathrm{KPB}$ (Potassium Phosphate Buffer). The sample was centrifuged at $8000 \mathrm{rpm}$ at $4^{\circ} \mathrm{C}$ for $20 \mathrm{~min}$. The supernatants were transferred into $1.5 \mathrm{~mL}$ eppendorf tube and optical density (OD) was measured at $280 \mathrm{~nm}$ by using biospectrophotometer (Eppendorf). Crude protein sample were further diluted (1:10) for SOD and CAT enzymatic assays and was stored at $-20{ }^{\circ} \mathrm{C}$ till further use.

\subsection{Superoxide Dismutase (SOD) enzymatic assay}

The principle behind SOD (EC 1.15.1.1) activity assay was the inhibition of reduction of nitrobluetetrazolium (NBT) by super oxide. In the presence of $\mathrm{O}_{2}$, riboflavin excitation occurs and methionine acts as a potent electron donor to generate superoxide anions. SOD assay is based on this phenomenon. The reduction of NBT by superoxide radicals gave purple color that was estimated 
at $560 \mathrm{~nm}$ using spectrophotometer [23, 24]. "One unit of SOD activity is defined as the amount of enzyme causing half the maximum inhibition of reduction of NBT under the specified conditions".

SOD assay was performed as described by [24] with little modification. The reaction mixture contained $20 \mu \mathrm{L}$ of $250 \mathrm{mM}$ Methionin (SRL, Cat\# 19305), $5 \mu \mathrm{L}$ of $10 \mathrm{mM}$ NBT (SRL, Cat\# 11207), $25 \mu \mathrm{L}$ of $1 \mathrm{M} \mathrm{KPB}, 0.5 \mu \mathrm{L}$ of $100 \mathrm{mM}$ EDTA (SRL, Cat\# 54960 ), $25 \mu \mathrm{L}$ of $1 \mathrm{M} \mathrm{Na} \mathrm{CO}_{3}$ and $380 \mu \mathrm{L}$ of distilled water with $40.5 \mu \mathrm{L}$ of desired diluted protein samples. $2 \mu \mathrm{L}$ of $1 \mathrm{mM}$ riboflavin (SRL, Cat\# 34392) was added at last and the total volume of reaction mixture was $500 \mu \mathrm{L}$. It was kept under white light for 8 min. The purple color was formed and the optical density (OD) was measured at 560nm using biospectrophotometer (Eppendorf).

\subsection{Catalase (CAT) Assay}

CAT enzymatic (EC 1.11.1.6) activity was measured according to the method described by [24]. The assay is based on the consumption of $\mathrm{H}_{2} \mathrm{O}_{2}$ in the presence of the enzyme source at $25^{\circ} \mathrm{C}$. The reaction mixture contained $30 \% \mathrm{H}_{2} \mathrm{O}_{2}, 50 \mathrm{mM} \mathrm{KPB}$ and $34 \mu \mathrm{L}$ of diluted protein samples from flies fed on normal diet and on $0.15 \mathrm{M}, 0.3 \mathrm{M}, 0.45 \mathrm{M}$ and $0.6 \mathrm{M}$ citric acid mixed diet. The OD $(240 \mathrm{~nm})$ of reaction mixture was taken immediately at $0 \mathrm{~min}$ and at 5 min by using biospectrophotometer.

One unit of enzyme is the amount of enzyme required to convert $1 \mathrm{~mol}$ of $\mathrm{H}_{2} \mathrm{O}_{2}$ to product in 1 second. Enzyme activity was expressed as units per milligram of protein.

\subsection{Oil Red O staining}

This was performed to visualize the lipid droplets of fat body cells in Drosophila tissues. This was done according to the method described in [25]. For this, fat body cells from third instar Drosophila larvae were dissected out in 1X PBS (pH 7.4), fixed in $4 \%$ para-formaldehyde for $20 \mathrm{~min}$ at room temperature and washed twice with 1X PBS. The tissues were stained in freshly prepared 0.1\% Oil Red O dye (Sigma Aldrich, USA, Cat\# 0625$100 \mathrm{G}$ ) in isopropanol (6 part of Oil Red O dye and 4 part of distilled water) for $30 \mathrm{~min}$ at room temperature. The tissues were washed first in distilled water followed by $60 \%$ isopropanol (to remove excess stain) and in $1 \mathrm{X}$ PBS. The tissues were mounted on slide using $2.5 \%$ DABCO mounting media and examined under Leica TCS SP5II laser scanning confocal microscope.

\subsection{Analysis of transcript levels of Brummer \& FAS in Drosophila melanogaster}

This was performed to examine the fat anabolism/ catabolism in citric acid monohydrate supplemented flies. For this, we examined the expression level of Fatty acid synthase (FAS) and Brummer (Fatty acid lyase) genes in citric acid (monohydrate) supplemented flies.

\subsection{RNA isolation}

Total RNA was isolated from 30 days old control and citric acid fed flies using TRIzol ${ }^{\circledR}$ reagent (Ambion/RNA, by Life technology, Cat\# 15596-018) following the manufacturer's instructions. Extracted RNAs were resuspended in Ultra pure ${ }^{\mathrm{TM}}$ distilled water (DNAse, RNAse free) (Invitrogen Cat\# 10977015). The quality as well as the quantity $\left(A_{260} / A_{280}\right.$ ratio) of the isolated RNA was verified through NanoDrop Spectrophotometer (Eppendorf).

\section{Complementary DNA (cDNA) synthesis}

The cDNA was synthesized from total RNA extracted from control and $0.15 \mathrm{M}$ and $0.3 \mathrm{M}$ citric acid monohydrate fed flies by using RevertAid first strand cDNA synthesis kit (Molecular Biology, Thermo scientific, Cat \# K1622). Each reaction mixture consist of RNA template $(2 \mu \mathrm{g})$, Oligo $(\mathrm{dT})_{18}$ $(1 \mu \mathrm{L}), 5 \mathrm{X}$ Reaction Buffer $(4 \mu \mathrm{L})$, RiboLockRNase Inhibitor (RI) $(1 \mu \mathrm{L}), 10 \mathrm{mM}$ dNTP Mix $(2 \mu \mathrm{L})$, RevertAid ${ }^{\mathrm{TM}}$ M-MuLV Reverse Transcriptase $(\mathrm{RT})(1 \mu \mathrm{L})$ and nucleases free water to make a final volume of $20 \mu \mathrm{L}$. The cDNA was stored at $-20^{\circ} \mathrm{C}$ till further use.

\subsection{Polymerase chain reaction (PCR)}

The synthesized cDNA $(\sim 1 \mu \mathrm{L})$ from control and $0.15 \mathrm{M}$ \& $0.3 \mathrm{M}$ citric acid fed flies were used for PCR amplification in a thermocycler (S1000TM Thermal cycler, Bio-Rad, CA, USA) using specific primers for the Drosophila Brummer \& FAS gene (Table 1). Rp49 gene specific primers were used as an endogenous control. The amplicons were separated on a $2 \%$ agarose gel containing ethidium bromide at $5 \mathrm{~V} \mathrm{~cm}^{-1}$ and visualized under a gel doc imaging system SL 3500 X-Press (VilberLourmat, France).

Table 1: Primers sequence used for PCR.

\begin{tabular}{ll}
\hline Brummer $(\boldsymbol{F})$ & 5'TCCCGAGTTTCTGTCCAAGT-3' \\
$\boldsymbol{B r u m m e r}(\boldsymbol{R})$ & 5'-GCGTCCTTTCTGTGCTTCTT-3' \\
$\boldsymbol{F A S}(\boldsymbol{F})$ & 5'-CGGAGAAGAGTTACATCCTG-3' \\
$\boldsymbol{F A S}(\boldsymbol{R})$ & 5'-CAATCACCACCTTTACGC-3' \\
$\boldsymbol{R p 4 9}(\boldsymbol{F})$ & 5'AATCTCCTTGCGCTTCTT-3' \\
$\boldsymbol{R p 4 9}(\boldsymbol{R})$ & 5'AGTATCTGATGCCCAACA-3' \\
\hline
\end{tabular}

\subsection{Statistical Analysis}

All the analyses were carried out in triplicate and expressed as mean \pm SEM. The analyses were carried out using the GraphPad Prism software, version 5.0. The difference among control and citric acid fed flies were compared by one way analysis of variance (ANOVA).

\section{RESULTS AND DISCUSSION}

\subsection{Supplementation of citric acid monohydrate $(0.15 \mathrm{M} \&$ $0.30 \mathrm{M})$ reduces body weight in Drosophila melanogaster}

The effect of citric acid monohydrate supplementation was studied by feeding the flies on normal diet and diet mixed with citric acid monohydrate $(0.15 \mathrm{M} \& 0.3 \mathrm{M})$. The mean body weight of Oregon $R^{+}$male flies fed on normal diet was $0.0008 \mathrm{~g}$. While the mean body weight of OregonR $^{+}$flies fed on $0.15 \mathrm{M}$ and $0.3 \mathrm{M}$ citric acid monohydrate mixed diets were $0.0007 \mathrm{~g}$ and $0.00065 \mathrm{~g}$, respectively (Fig. 1A) $(\mathrm{P}<0.05)$. Similarly, the mean body weight of Oregon $R^{+}$female flies fed on normal diet was $0.0012 \mathrm{~g}$. While the mean body weight of OregonR $^{+}$flies fed on 
$0.15 \mathrm{M}$ and $0.3 \mathrm{M}$ citric acid monohydrate mixed diets were $0.0010 \mathrm{~g}$ and $0.0009 \mathrm{~g}$, respectively (Fig. 1B) $(\mathrm{P}<0.05)$. These results showed the significant reductions in body weight of citric acid monohydrate supplemented flies.
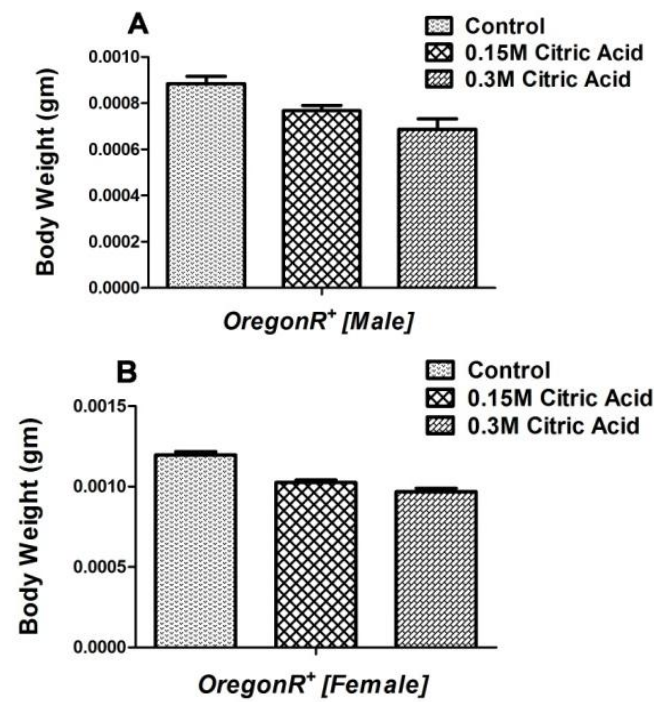

Fig.1: Citric acid supplementation results in reduction of body weight in Drosophila melanogaster. Graph showing the mean body weight of $\mathrm{OregonR}^{+}$ male (A) and female flies (B) fed on normal diet and diet mixed with $0.15 \mathrm{M} \&$ $0.3 \mathrm{M}$ citric acid monohydrate. The flies (male \& female) fed on $0.15 \mathrm{M} \& 0.3 \mathrm{M}$ citric acid monohydrate showing a significant reduction in mean body weight as compared to the flies fed on normal diet. Total 100 flies were examined for each group. Error bars represents Mean \pm SEM (P value $<0.05)$.

Since, citric acid is an intermediate in the Kreb's cycle (TCA or Kreb's cycle) and it poured more energy (ATP) to the cell by accelerating the metabolism. ${ }^{[5]}$ Thus, the reduction in body weight of citric acid fed flies might be due to an increase in metabolism. This observation also supports a previous study by ${ }^{[3]}$, supplementation of citric acid monohydrate reduces body mass in mice.

\subsection{Supplementation of citric acid monohydrate improves locomotor activity in Drosophila}

Since, locomotor activity is an integral component of most animal behaviors, and many human health problems are associated with locomotors deficits. In order to check the effect of citric acid on locomotor activity in Drosophila, locomotor assay was performed in 10 and 20 days flies fed on normal and $0.15 \mathrm{M}$ and $0.3 \mathrm{M}$ citric acid mixed diet. In locomotor test of OregonR ${ }^{+}$ flies (10 days) fed on normal diet, $77.5 \%$ flies crossed $10 \mathrm{~cm} / 10$ sec while this fly $\%$ increased up to $87 \%$ and $97.5 \%$ when the flies were fed on $0.15 \mathrm{M}$ and $0.3 \mathrm{M}$ citric acid mixed food (Fig. 2A). In 20 days of locomotor activity test of OregonR $^{+}$flies fed on normal diet, $60 \%$ flies crossed $10 \mathrm{~cm} / 10 \mathrm{sec}$ while this fly $\%$ increased up to $72.5 \%$ and $77.5 \%$ when the flies were fed on $0.15 \mathrm{M}$ and $0.3 \mathrm{M}$ citric acid mixed food (Fig. 2A) $(\mathrm{P}<0.05)$. This result suggest a significant increase in locomotor activity of OregonR $^{+}$flies fed on $0.15 \mathrm{M}$ and $0.3 \mathrm{M}$ citric acid mixed diet as compared to the flies fed on normal diet. Since, locomotor impairment is one of the key feature of neurodegenerative disease in human as well as in animal models, thus, to further confirm our findings, we performed the locomotor activity test in Alzheimeric flies $\left(G M R A \beta_{42}{ }^{K 52}\right.$; $G M R A \beta_{42}{ }^{K 53}$ ). The locomotor activity test of 10 days old $G M R A \beta_{42}{ }^{K 52} ; G M R A \beta_{42}{ }^{K 53}$ flies fed on normal diet, $70 \%$ flies crossed $10 \mathrm{~cm}$ distance in 10 seconds while this fly $\%$ increased up to $85 \%$ and $90 \%$ when the flies were fed on $0.15 \mathrm{M}$ and $0.3 \mathrm{M}$ citric acid mixed food. Similarly, in 20 days test $52.5 \% G M R A \beta_{42}{ }^{K 52}$; $G M R A \beta_{42}{ }^{K 53}$ flies, fed on normal diet crossed $10 \mathrm{~cm} / 10 \mathrm{sec}$ while this fly $\%$ increased up to $67.5 \%$ and $70 \%$ when the flies were fed on $0.15 \mathrm{M}$ and $0.3 \mathrm{M}$ citric acid mixed food (Fig. 2B) $(\mathrm{P}<0.05)$. This result further confirmed above observations. The increase in locomotor activity might be due to cumulative effect of reduction in body weight and an increase in cellular energy level.
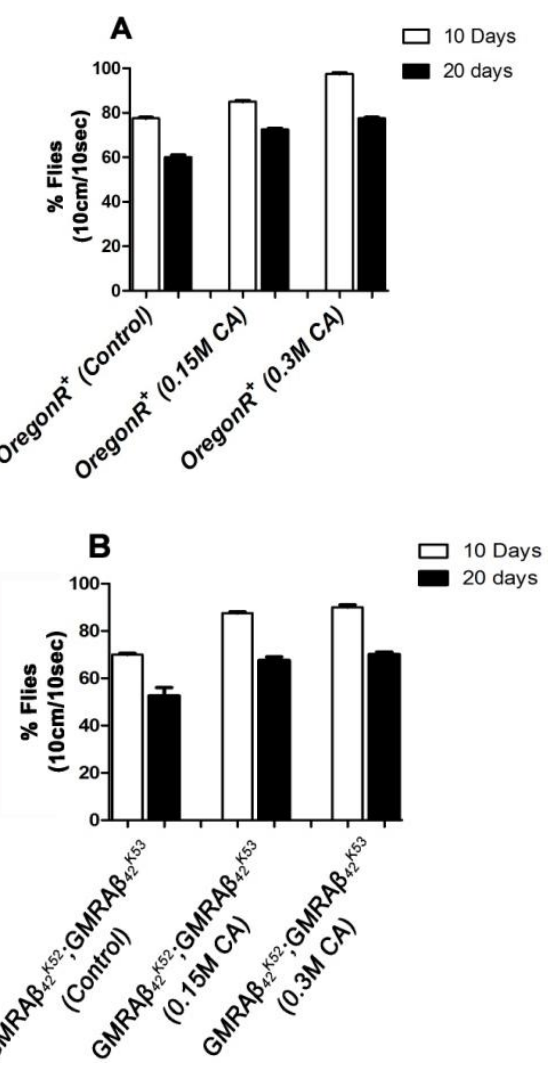

Fig. 2: Citric acid supplementation improves locomotor activity in Drosophila melanogaster. Above graphs shows locomotor activity of 10 and 20 days old OregonR ${ }^{+} \&$ GMRA $\beta_{42}{ }^{K 52} ; G M R A \beta_{42}{ }^{K 53}$ flies. (A) Locomotor activity of Oregon $^{+}$flies, fed on normal diet and on $0.15 \mathrm{M}$ and $0.3 \mathrm{M}$ citric acid monohydrate mixed diet. Graph A showing an increase in locomotor activity in $0.15 \mathrm{M}$ and $0.3 \mathrm{M}$ citric acid monohydrate fed $10 \& 20$ days old flies as compared to the control. (B) Locomotor activity of Alzheimeric fly

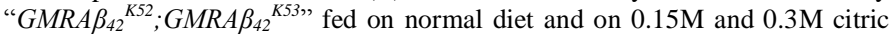
acid monohydrate mixed diet. Graph showing an improved locomotor activity in $0.15 \mathrm{M}$ and $0.3 \mathrm{M}$ citric acid monohydrate fed $10 \& 20$ days old flies as compared to the control. Total 100 flies were taken per assay. Error bars represents Mean $\pm \operatorname{SEM}(\mathrm{P}<0.05)$. $(\mathrm{CA}=$ Citric Acid $)$.

\subsection{Supplementation of citric acid monohydrate reduces paraquat induced oxidative stress in Drosophila}

As, it is well known that plants and plants based components possess great anti-oxidant properties, thus, to examine 
the anti-oxidant activity associated with citric acid monohydrate, we performed SOD and CAT enzymatic assays in flies fed on normal and citric acid mixed diet. For this OregonR $^{+}$flies were fed on $1 \%$ sucrose (control), $20 \mathrm{mM}$ paraquat and $0.15 \mathrm{M}, 0.3 \mathrm{M}$, $0.45 \mathrm{M}$ and $0.6 \mathrm{M}$ citric acid monohydrate mixed diet. We used PQ a herbicides, commonly used to induce oxidative stress in flies [26]. For this OregonR ${ }^{+}$flies were fed on filter paper socked with $1 \%$ sucrose solution (control), $1 \%$ sucrose solution $+20 \mathrm{mM}$ PQ and $1 \%$ sucrose solution $+20 \mathrm{mM}$ PQ in combination of different concentration of citric acid monohydrate $(0.15 \mathrm{M}, 0.3 \mathrm{M}, 0.45 \mathrm{M}$ and $0.6 \mathrm{M})$. It was observed that flies fed on $20 \mathrm{mM}$ PQ had an induction of SOD and CAT enzymes activities while flies fed on PQ in combination of $0.15 \mathrm{M}, 0.3 \mathrm{M}, 0.45 \mathrm{M}$ and $0.6 \mathrm{M}$ citric acid showed a significant reduction $(\mathrm{P}>0.05)$ in $\mathrm{SOD}$ (Fig. 3A) and CAT (Fig. 3B) enzymes activities. This result suggested that supplementation of citric acid reduces oxidative stress in Drosophila melanogaster and possess anti-oxidant property.
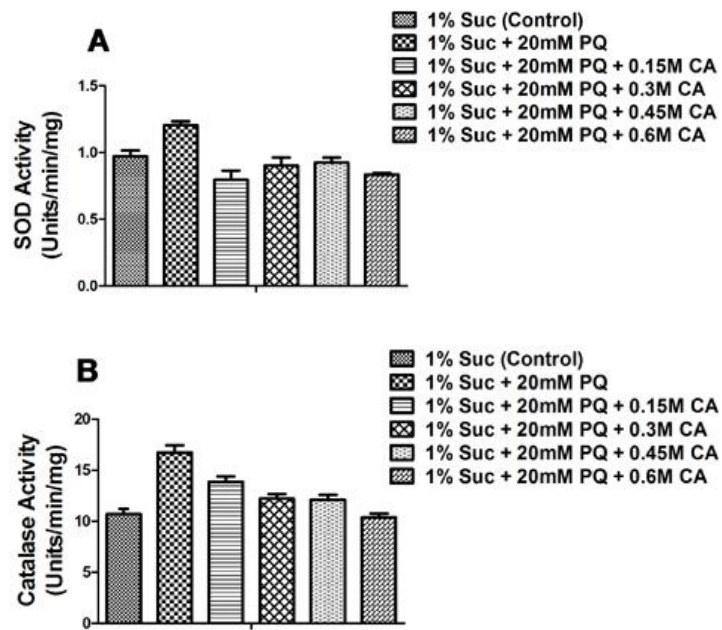

Fig. 3: Citric acid reduces paraquat (PQ) induced oxidative stress in Drosophila melanogaster. (A) Above graph showing an increase in SOD activity in PQ fed flies, as compared to the control (flies fed on $1 \%$ sucrose) while Oregon $^{+}$flies fed on PQ in combination of $0.15 \mathrm{M}$. $0.3 \mathrm{M}, 0.45 \mathrm{M}$ and $0.6 \mathrm{M}$ citric acid monohydrate shows a significant reduction in SOD activity. (B) Graph showing an increase in CAT activity in PQ fed flies while a significant reduction in CAT activity in flies, fed on PQ in combination of $0.15 \mathrm{M}$. $0.3 \mathrm{M}, 0.45 \mathrm{M}$ and $0.6 \mathrm{M}$ citric acid monohydrate as compared to the control (flies fed on $1 \%$ sucrose) flies. Error bars represents Mean \pm SEM (P value $>0.05)$.

\subsection{Supplementation of citric acid monohydrate increases fat body size in Drosophila}

As shown above supplementation of citric acid reduces body weight, improves locomotor activity and reduced oxidative stress in Drosophila. Thus, in order to find out the mechanism behind the same, the fat content in Oregon ${ }^{+}$flies, fed on normal diet and on $0.15 \mathrm{M} \& 0.3 \mathrm{M}$ citric acid monohydrate mixed diet were examined. For this, fat bodies were dissected out from the $3^{\text {rd }}$ instar Drosophila larva and were stained with Oil Red O dye (a marker for lipid droplets) and the lipid droplets (LDs) size was measured. We observed $6 \mu \mathrm{m}$ average size of LDs in OregonR ${ }^{+}$ flies fed on normal diet (Fig. 4A \& D) while this size was increases up to $12 \mu \mathrm{m}$ (Fig. $4 \mathrm{~B} \& \mathrm{D})$ and $14 \mu \mathrm{m}$ (Fig. 4C \& D) in flies fed on $0.15 \mathrm{M}$ and $0.3 \mathrm{M}$ citric acid monohydrate mixed diet, respectively. This result clearly suggests an increase in fatty acid synthesis in fat body of flies fed on $0.15 \mathrm{M}$ and $0.3 \mathrm{M}$ citric acid monohydrate mixed diet.

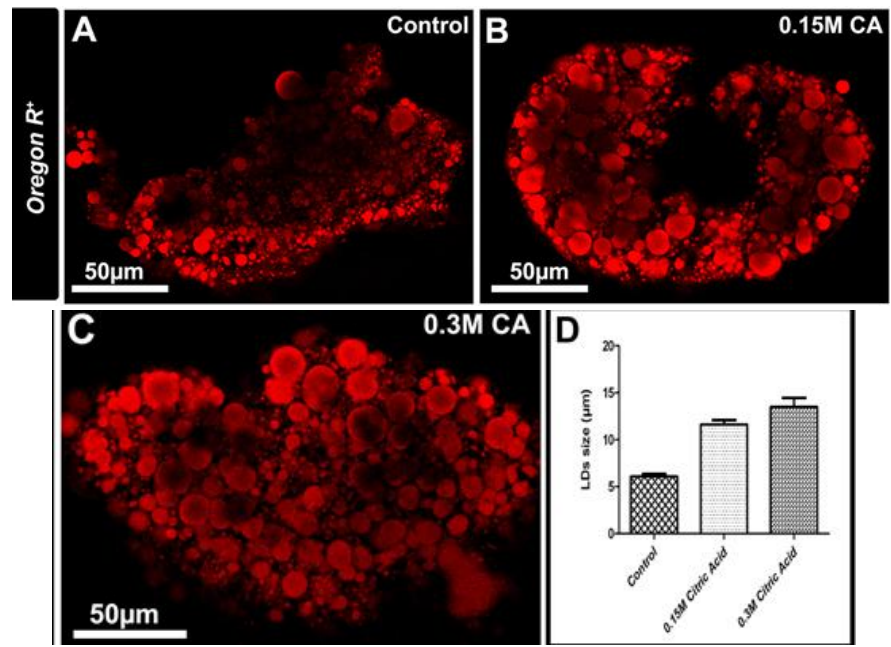

Fig. 4: Oil Red $\mathrm{O}$ staining in fat body tissues in Drosophila melanogaster. Oil Red O staining in fat body tissues of OregonR $^{+}$flies fed on normal diet (A), on $0.15 \mathrm{M}$ citric acid (B) and $0.3 \mathrm{M}$ citric acid (C). The histogram shows a significant increase in fat body size in citric acid supplemented flies as compared to the flies fed on normal diet. Error bars represents Mean \pm SEM (P value $>0.0001)$.

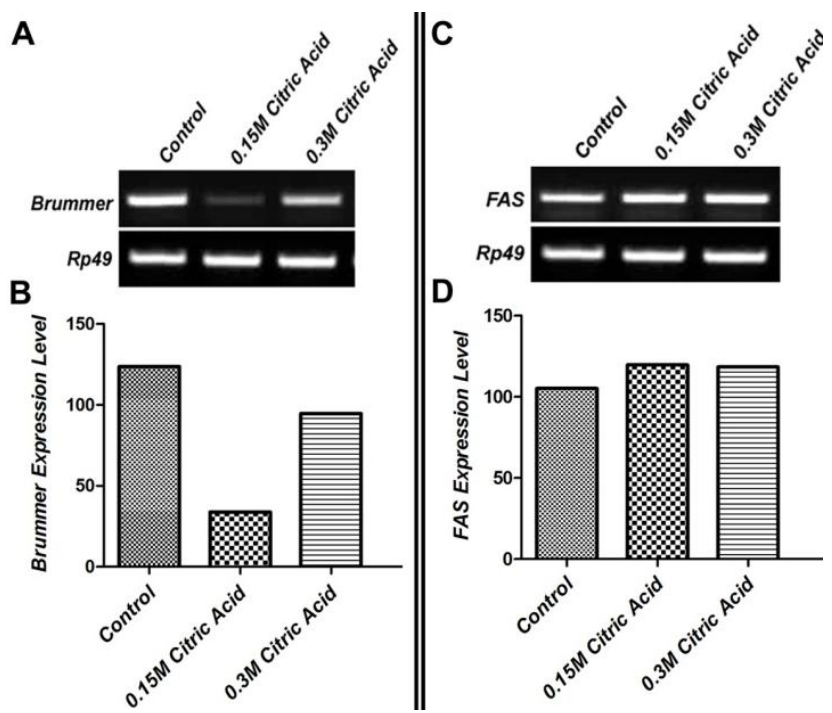

Fig. 5: RT-PCR analysis of Brummer (bmm) and Fatty acid synthase (FAS) genes in OregonR $^{+}$flies fed on normal and citric acid mixed diet. RT-PCR analysis showing Brummer ( $\mathrm{bmm}$ ) and $F A S$ expression level in 30 days old Oregon $R^{+}$flies fed on normal diet and on $0.15 \mathrm{M}$ and $0.3 \mathrm{M}$ citric acid mixed diet. $\mathrm{bmm}$ expression level was decreased in $0.15 \mathrm{M} \& 0.3 \mathrm{M}$ citric acid monohydrate fed flies (A \& B) while $F A S$ expression level was increased significantly in $0.15 \mathrm{M} \& 0.3 \mathrm{M}$ citric acid monohydrate fed flies $(\mathrm{C} \& \mathrm{D})$.

In order to further confirm our findings, we examined the level of fatty acid synthesis by measuring the expression level of two genes associated with fat metabolism: Fatty acid synthase (FAS) and Brummer (bmm) (Fatty acid Lyase) in OregonR ${ }^{+}$flies fed on normal diet and citric acid $(0.15 \mathrm{M}$ and $0.3 \mathrm{M})$ mixed diet. This was done by performing RT-PCR analysis using gene specific primers. We observed that bmm expression level was 
significantly reduced (Fig. 5A \& B) and FAS expression level was significantly increased (Fig. 5C \& D) in flies fed on $0.15 \mathrm{M}$ and $0.3 \mathrm{M}$ citric acid monohydrate mixed diet as compared to the flies fed on normal diet. It is well known that bmm is fat mobilizing enzyme and plays a vital role in lypolysis. bmm gene is responsible for encoding fat body lipid droplet associated TAG-lipase. An earlier report by [27] suggested that loss of function of bmm gene in Drosophila results in obesity. The other enzyme FAS is responsible for fatty acid synthesis and its expression was increases in $0.15 \mathrm{M}$ and $0.3 \mathrm{M}$ citric acid supplemented flies. It might be possible that supplementation of $0.15 \mathrm{M}$ and $0.3 \mathrm{M}$ citric acid monohydrate inhibit lipid breakdown by decreasing $\mathrm{bmm}$ gene and an increase of fatty acid synthesis by increasing FAS enzymatic activity in Drosophila. Thus, the increase in lipid droplets size represents an increase in fatty acid synthesis hence an increase in fat storage in the form of Triglycerides [28]. The reason behind the increase in locomotor activity in citric acid fed flies might be due to the change in energy status of the cell by an increase of intracellular citrate level.

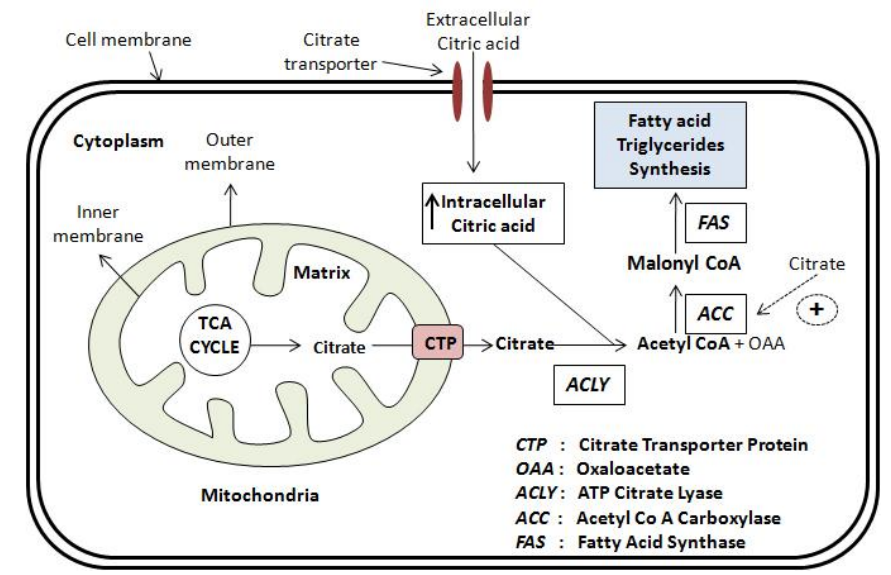

Fig.6: Schematic diagram representing the possible mechanism of fatty acid synthesis by supplementation of citric acid in Drosophila melanogaster. Supplementation of citric acid increases intracellular citric acid level and activates ATP:Citratelyase (ACLY) enzyme. Activation of ACLY will produce Acetyl-CoA and oxaloacetate by utilizing citrate molecule. Acetyl-CoA will be converted into manonyl Co-A (FAs building block) by Acetyl-CoA carboxylase $(A C C)$ enzyme. $A C C$ will be also allosterically regulated by citrate. Manonyl Co-A will be converted into fatty acids and triglycerides by Fatty acid synthase (FAS) enzyme which will be ultimately stored in fat body tissue of Drosophila.

\section{CONCLUSIONS}

In conclusion, the present study suggested that supplementation of citric acid improves health span in Drosophila melanogaster and recommend the increase use of citrus fruit that is rich source of citric acid. The EFSA: European Food Safety Authority [29] has already recommended that use of citric acid monohydrate in food or food additives is safe for the consumer, it does not lead any environmental risk and can be used as preservative without restriction in feed for all animal species.

\section{ACKNOWLEDGEMENTS}

We are grateful to Prof. J. K. Roy, Banaras Hindu University, Varanasi, India, for fly stocks. The authors acknowledge the instrumentation facility supported by DBT, India and Puri Foundation for education in India at IIAR.

\section{REFERENCES}

1. Kliewer WK. Sugars and Organic Acids of Vitis Vinifera. Plant Physiol. 1996; 41: 923-931.

2. Ellis H, Riki Van DB, Jaap N, Gunter F. Biosynthesis and root exudation of citric and malic acids in phosphate-starved rape plants. New Phytologist. 1992; 122: 675-680.

3. Wachman A, Bernstein DS. Diet and osteoporosis. The Lancet. 1968; 291: 958-959.

4. Beeckmans S. Some structural and regulatory aspects of citrate synthase. Int J Biochem. 1984; 16: 341-51.

5. Paul AS. The molecular physiology of citrate. Nature. 1965; 205: 766-770.

6. Mycielska ME, Patel A, Rizaner N, Mazurek MP, Keun H, Patel A, Ganapathy V, Djamgoz MB. Citrate transport and metabolism in mammalian cells Prostate epithelial cells and prostate cancer. BioEssays. 2009; 31: 10-20.

7. Saha AK, Vavvas D, Kurowski TG, Apazidis A, Witters LA, Shafrir E, Ruderman NB. Malonyl-CoA regulation in skeletal muscle: its link to cell citrate and the glucose-fatty acid cycle. Am J Physiol. 1997; 272: E641-8.

8. Ohlrogge JB, Jaworski JG, Post-Beittenmiller D. De novo fatty acid biosynthesis, In: Moore TS, Editors. Lipid Metabolism in Plants. Boca Raton, FL: CRC Press. 1993. pp. 3-32.

9. Casani S, Gómez-Pastor R, Matallana E, Paricio N. Antioxidant compound supplementation prevents oxidative damage in a Drosophila model of Parkinson's disease. Free Radic Biol Med. 2013; 61: 151-60.

10. Missirlis F, Rahlfs S, Dimopoulos N, Bauer H, Becker K, Hilliker A, Phillips JP, Jackle H. A putative glutathione peroxidase of Drosophila encodes a thioredoxin peroxidase that provides resistance against oxidative stress but fails to complement a lack of catalase activity. Biol Chem. 2003; 384:463-472.

11. Serkan Y, Fatma U, Deniz, Huseyin A. Clastogenic effects of food additive citric acid in human peripheral lymphocytes. Cytotechnology. 2008; 56: 137-144.

12. Prüßing K, Voigt A, Schulz JB. Drosophila melanogaster as a model organism for Alzheimer's disease. Mol Neurodegener. $2013 ; 22: 8-35$.

13. Sidow A, Thomas WK. A molecular evolutionary framework for eukaryotic model organism. Curr Biol. 1994; 4: 596-603.

14. Rubin GM, Lewis EB. A brief history of Drosophila's contributions to genome research. Science. 2000; 287: 2216-2218.

15. Adams MD, Celniker SE, Holt RA, Evans CA, Gocayne JD, Amanatides PG, et al. The Genome Sequence of Drosophila melanogaster. Science. 2000; 287: 2185-2195.

16. HYE C, Bonini NM. Drosophila models of human neurodegenerative disease. Cell Death Differ. 2000; 7: 1075-1080.

17. Tiwari AK, Pragya P, Ravi Ram K, Chowdhuri DK. Environmental chemical mediated male reproductive toxicity: Drosophila melanogaster as an alternate animal model. Theriogenology. 2011; 76: 197-216.

18. Kumar A, Dave M, Pant DC, Laxkar R, Tiwari AK. Vinca rosea leaf extract supplementation leads to developmental delay and several phenotypic anomalies in Drosophila melanogaster. Toxicol. \& Environ. Chem. 2013; 95: 635-645.

19. Pant DC, Dave M, Tiwari AK. Wheatgrass (Triticum aestivum L.) Supplementation Promotes Longevity in Drosophila melanogaster. Annals of Plant Sciences. 2013; 02: 49-54.

20. Hirth F. Drosophila melanogaster in the Study of Human Neurodegeneration. CNS Neurol Disord Drug Targets. 2010; 9: 504-523. 
21. Van DD, De Deyn PP. Animal models in the drug discovery pipeline for Alzheimer's disease. Br J Pharmacol. 2011; 164: $1285-1300$.

22. Feany MB, Bender WW. A Drosophila model of Parkinson's disease. Nature. 2000; 404: 394-8.

23. Kajari D, Luna S, Chainy GBN. A modified spectrophotometric assay of superoxide dismutase using nitrite formation by superoxide radicals. Ind. J Biochem \& Biophy. 1999; 37: 201-204.

24. Rukmini MS, D’Souza B, D’Souza V. Superoxide dismutase and catalase activities and their correlation with malondialdehyde in schizophrenic patients. Ind. J Clin. Biochem. 2004; 19;114-118.

25. Banerjee KK, Ayub C, Sengupta S, Kolthur-Seetharam U. dSir2 deficiency in the fatbody, but not muscles, affects systemic insulin signaling, fat mobilization and starvation survival in flies. Aging (Albany NY). 2012; 4: 206-23.

26. Bus JS, Gibson JE. Paraquat: model for oxidant-initiated toxicity. Environ Health Perspect. 1984; 55: 37-46.

27. Grönke S, Mildner A, Fellert S, Tennagels N, Petry S, Müller G, Jäckle H, Kühnlein RP. Brummer lipase is an evolutionary conserved fat storage regulator in Drosophila. Cell Metab. 2005; 1: 323-30.
28. Estela A, Soulages JL. Insect fat body: energy, metabolism and regulation. Annu Rev Entomol. 2010; 55: 207-225.

29. Aquilina G, Vasileios B, Lourdes BMD, et al. Scientific Opinion on the safety and efficacy of citric acid when used as a technological additive (acidity regulator) for all animal species. EFSA. 2015; 13: 4010.

\section{How to cite this article:}

Panchal K, Patel K, Tiwari AK. Dietary Supplementation of Citric acid (monohydrate) Improves Health Span in Drosophila melanogaster. J App Biol Biotech. 2016; 4 (02): 060-066. DOI: 10.7324/JABB.2016.40209 